\title{
Assessment of Ataxia Rating Scales and Cerebellar Functional Tests: Critique and Recommendations
}

Santiago Perez-Lloret, MD, PhD, ${ }^{1,2,3^{\star}}$ (1) Bart van de Warrenburg, MD, PhD, ${ }^{4}$ Malco Rossi, MD, PhD, ${ }^{5}$ (D) Carmen Rodríguez-Blázquez, PhD, MSc, ${ }^{6}$ (iD) Theresa Zesiewicz, MD, FAAN, ${ }^{7}$ Jonas A.M. Saute, MD, PhD, $, 8,9,10,11$ Alexandra Durr, MD, PhD, ${ }^{12}$ Masatoyo Nishizawa, MD, PhD, ${ }^{13}$ Pablo Martinez-Martin, MD, PhD, ${ }^{14}$ (1)

Glenn T. Stebbins, $\mathrm{PhD},{ }^{15}$ Anette Schrag, MD, PhD, ${ }^{16}$ (D) and Matej Skorvanek, MD, PhD, ${ }^{17,18}$ and members of the MDS Rating Scales Review Committee

\author{
${ }^{1}$ National Research Council (CAECIHS-UAI, CONICET), Buenos Aires, Argentina \\ ${ }^{2}$ Faculty of Medicine, Pontifical Catholic University of Argentina, Buenos Aires, Argentina \\ ${ }^{3}$ Department of Physiology, Faculty of Medicine, University of Buenos Aires, Buenos Aires, Argentina \\ ${ }^{4}$ Donders Institute for Brain, Cognition and Behavior, Department of Neurology, Center of Expertise for Parkinson and Movement Disorders, \\ Radboud University Medical Center, Nijmegen, The Netherlands \\ ${ }^{5}$ Movement Disorders Section, Raul Carrea Institute for Neurological Research, Buenos Aires, Argentina \\ ${ }^{6}$ National Centre of Epidemiology, Institute of Health Carlos III and CIBERNED, Madrid, Spain \\ ${ }^{7}$ Department of Neurology, University of South Florida, Tampa, Florida, USA \\ ${ }^{8}$ Medical Genetics Division, Hospital de Clínicas de Porto Alegre (HCPA), Porto Alegre, Brazil \\ ${ }^{9}$ Neurology Division, Hospital de Clínicas de Porto Alegre (HCPA), Porto Alegre, Brazil \\ ${ }^{10}$ Postgraduate Program in Medicine: Medical Sciences, Universidade Federal do Rio Grande do Sul, Porto Alegre, Brazil \\ ${ }^{11}$ Department of Internal Medicine, Universidade Federal do Rio Grande do Sul, Porto Alegre, Brazil \\ ${ }^{12}$ Sorbonne Université, Institut du Cerveau-Paris Brain Institute (ICM), AP-HP, INSERM, CNRS, University Hospital Pitié-Salpêtrière, Paris, France \\ ${ }^{13}$ Brain Research Institute, Niigata University, Niigata, Japan \\ ${ }^{14}$ Center for Networked Biomedical Research in Neurodegenerative Diseases (CIBERNED), Carlos III Institute of Health, Madrid, Spain \\ ${ }^{15}$ Department of Neurological Sciences, Rush University Medical Center, Chicago, Illinois, USA \\ ${ }^{16}$ Department of Clinical Neurosciences, UCL Institute of Neurology, Royal Free Campus, London, United Kingdom \\ ${ }^{17}$ Department of Neurology, Faculty of Medicine, P. J. Safarik University, Kosice, Slovak Republic \\ ${ }^{18}$ Department of Neurology, University Hospital L. Pasteur, Kosice, Slovak Republic
}

ABSTRACT: Background: We assessed the clinimetric properties of ataxia rating scales and functional tests, and made recommendations regarding their use.

Methods: A systematic literature search was conducted to identify the instruments used to rate ataxia symptoms. The identified rating scales and functional ability tests were reviewed and ranked by the panel as "recommended," "suggested," or "listed" for the assessment of patients with discrete cerebellar disorders, using previously established criteria.

Results: We reviewed 14 instruments (9 rating scales and 5 functional tests). "Recommended" rating scales for the assessment of symptoms severity were: for Friedreich's ataxia, the Friedreich's Ataxia Rating Scale, the International Cooperative Ataxia Rating Scale (ICARS), and the Scale for the Assessment and Rating of
Ataxia (SARA); for spinocerebellar ataxias, ICARS and SARA; for ataxia telangiectasia: ICARS and SARA; for brain tumors, SARA; for congenital disorder of glycosylation-phosphomannomutase-2 deficiency, ICARS; for cerebellar symptoms in multiple sclerosis, ICARS; for cerebellar symptoms in multiple system atrophy: Unified Multiple System Atrophy Rating Scale and ICARS; and for fragile X-associated tremor ataxia syndrome, ICARS. "Recommended" functional tests were: for Friedreich's ataxia, Ataxia Functional Composite Score and Composite Cerebellar Functional Severity Score; and for spinocerebellar ataxias, Ataxia Functional Composite Score, Composite Cerebellar Functional Severity Score, and SCA Functional Index.

Conclusions: We identified some "recommended" scales and functional tests for the assessment of
*Correspondence to: Dr. Santiago Perez Lloret, National Research Council (CAECIHS-UAI, CONICET), Av. San Juan 951, C1147 Buenos Aires, Argentina; E-mail: santiagopl@conicet.gov.ar

The members of the MDS Committee on Rating Scales are listed as an Appendix.

Relevant conflicts of interest/financial disclosures: Nothing to report.

\section{Full financial disclosures and author roles may be found in the online version of this article.}

Received: 28 July 2020; Revised: 28 August 2020; Accepted: 8 September 2020

Published online in Wiley Online Library (wileyonlinelibrary.com). DOI: 10.1002/mds.28313 
PEREZ LLORET ET A L )

patients with major hereditary ataxias and other cerebellar disorders. The main limitations of these instruments include the limited assessment of patients in the more severe end of the spectrum and children. Further research in these populations is warranted. (C) 2020
International Parkinson and Movement Disorder Society

Key Words: ataxia; cerebellar disorders; rating scales; clinical trials; Friedreich's ataxia; spinocerebellar ataxia
Cerebellar disturbances are observed in a broad range of pathological conditions. ${ }^{1,2}$ The term ataxia is sometimes used to designate cerebellar diseases in general. ${ }^{1,3}$ Hereditary ataxias are a large and complex group of diseases that affect the cerebellum or its connections. ${ }^{2}$ According to a meta-analysis, which included 22 studies with a total of 14,539 patients from 16 countries, the most frequent dominant ataxias were spinocerebellar ataxia (SCA) type 3 (SCA3), SCA2, and SCA6, and the most frequent recessive ones were Friedreich's ataxia (FA), ataxia with oculomotor apraxia, and ataxia telangiectasia (AT) ${ }^{4}$

Clinical assessment of cerebellar disease symptoms can be achieved by clinical rating scales. ${ }^{5}$ Initially, it was suggested that cerebellar symptoms could be better captured by semiquantitative rating scales. ${ }^{3}$ Later on, quantitative functional assessment tools were introduced in an attempt to increase reliability in measures. ${ }^{6}$ Clinimetric properties of these instruments need to be critically considered before choosing one for the assessment of patients during clinical trials or in daily practice. Therefore, we set out to critically assess the clinimetric properties of available ataxia rating scales and functional tests, and to issue recommendations. The International Parkinson's and Movement Disorders Society (MDS) Rating Scales Program has been conducting clinimetric assessment of rating scales for more than a decade through the work of the MDS Rating Scales Review Committee.

\section{Methods}

\section{Administrative Organization and Critique Process}

The members of the committee appointed by the MDS Rating Scale Review Committee began by listing all available scales for the assessment of ataxia. Then the scales for further assessment were selected based on the criteria described later. Finally, each member was charged with assessing specific scales by using a standardized evaluation form. Members of the committee involved in the development of one of the scales selected for assessment refrained from participating in the assessment of that scale. The assessment forms were then reevaluated by a second reviewer and, finally, by an expert in clinimetric assessment.

After the revision process was finished, members reviewed results for all scales, and conclusions and recommendations were proposed. The final report was reviewed and approved by the MDS Rating Scales Review Committee.

\section{Literature Search Strategy and Selection of Instruments}

A systematic search was conducted via PubMed on studies published between January 1960 and January 2020 using appropriate search strings (see Part 2 of Supporting Information Appendix S1). Eligible papers had to be written in English, Spanish, French, or Portuguese.

To be selected, an instrument (ie, a scale or a functional test) had to have been used for the assessment of ataxia. Only data on the original scale were considered; that is, data gathered with scales' translations to other languages were not considered. Functional tests were evaluated when sophisticated, specialized equipment was not required to perform them.

\section{Evaluation of Clinimetric Properties and Recommendations}

All assessments were performed according to the methodology developed by the MDS Rating Scales Review Committee. ${ }^{7,8}$ Recommendations were based on scientifically sound studies, including populations of patients with discrete cerebellar disorders. Data from studies including more than one type of cerebellar disorder were retained only if results were available for each disorder covered.

An instrument was rated as "recommended" if it had been used in patients with any kind of ataxia, it had been used by groups other than the developer, and adequate clinimetrics supported its use. Only "positive" data (see Part 1 of Supporting Information Appendix S1) without conflicting or incomplete results on feasibility, acceptability, reliability, and validity were deemed as adequate. Instruments rated as "suggested" have been used in patients with cerebellar disorders and have been used by investigators other than the original developers. Finally, "listed" instruments were used only in patients with cerebellar disorders.

\section{Results}

Of the 16 instruments identified, 14 (9 rating scales, and 5 functional tests) were selected for further assessment (Table 1). The nine rating scales included in the assessment were Brief Ataxia Rating Scale (BARS), Disease Severity Index for Adults with Autosomal 
Recessive Spastic Ataxia of Charlevoix-Saguenay (DSIARSCAS), Friedreich's Ataxia Impact Scale (FAIS), Friedreich's Ataxia Rating Scale (FARS), Fragile Xassociated Tremor Ataxia Syndrome Rating Scale (FXTAS-RS), International Cooperative Ataxia Rating Scale (ICARS), Neurological Examination Score for Spinocerebellar Ataxia (NESSCA), Scale for the Assessment and Rating of Ataxia (SARA), and Unified Multiple System Atrophy Rating Scale (UMSARS) (Table 1). The five functional tests included for assessment were Ataxia Functional Composite Scale (AFCS), the APPCoo-Test, Composite Cerebellar Functional Severity Score (CCFS), Hevelius, and SCA Functional Index (SCAFI) (Table 1). The Inventory of Non-Ataxia Symptoms (INAS) and the Cerebellar Cognitive Affective/ Schmahmann syndrome scale were not selected for further assessment because they did not target ataxia symptoms.

A summary of the results of bibliographical searches is provided in Supporting Information Figure E-1 in Part 3 of Appendix S1.

Characteristics, clinimetric properties, and strengths and weaknesses of each instrument will be summarized in the following section. Clinimetric properties of the reviewed rating scales and functional tests are summarized in Tables 2 and 3. For the sake of brevity, only essential aspects of clinimetric assessment will be described for each scale, but full information can be found in Part 4 of Supporting Information Appendix S1. Recommendations can be found in Table 4.

\section{Rating Scales \\ Brief Ataxia Rating Scale}

Description of the Scale. The BARS was developed to overcome some of the main limitations of other ataxia scales, such as length and redundancies. ${ }^{9}$ The scale is completed by a trained health care professional, and it may take 3 to 5 minutes to complete. ${ }^{10}$ The scale is not copyrighted and can be found in the original publication. ${ }^{9}$

Clinimetric Properties There is no information on missingness and floor or ceiling effects. Interrater reliability was adequate in healthy children. ${ }^{11,12}$ Test-retest reliability was also good in healthy children. ${ }^{11}$ Internal consistency was adequate in three groups of patients with cerebellar disorders. ${ }^{9}$ In healthy children, BARS correlated significantly with ICARS $(r=0.77)$ and SARA $(\mathrm{r}=0.68) .{ }^{11}$ In patients with AT, BARS correlated with ICARS $(\mathrm{r}=0.93)$ and Clinical Global Impression $(\mathrm{r}=0.77) .{ }^{13}$ In children after surgical resection of posterior fossa tumors (ie, glioma, medulloblastoma, ependymoma, or schwannoma), BARS correlated with the Pediatric Evaluation of Disability Index $(\mathrm{r}=-0.75) .{ }^{12}$ BARS correlated with SARA $(\mathrm{r}=0.51)$ and INAS $(\mathrm{r}=0.49)$ scores in patients with SCA $7 .{ }^{14}$

Strengths and Weaknesses. BARS is a brief instrument that has shown adequate validity and reliability. Acceptability and sensitivity of change remain to be explored.

Conclusions BARS is "suggested" for the assessment of patients with SCA, brain tumors (BTs), and AT, because it has been used by groups other than the developer, but some clinimetric data remain to be explored.

\section{Disease Severity Index for Adults with Autosomal Recessive Spastic Ataxia of Charlevoix-Saguenay}

Description of the Scale. The Disease Severity Index for Adults with Autosomal Recessive Spastic Ataxia of Charlevoix-Saguenay (DSI-ARSACS) is the first scale specifically developed to assess patients with this disease. It includes eight items, one related to speech, two to upper limbs function, one to mobility, three to lower limbs function, and one to bladder dysfunction. ${ }^{15}$ The scale is in the public domain and can be obtained online at: https://savoirs.usherbrooke.ca/handle/11143/15277.

Clinimetric Properties. This scale has been used only by the original developers, and there is only one article available with validation data, which included 26 participants. ${ }^{15}$ No patient achieved minimal or maximal scores. Internal consistency was high. There is no information on missing data and reproducibility. DSIARSACS total score correlated with SARA $(\mathrm{r}=0.95)$, Barthel index $(r=0.90)$, 9HPT (9-hole pegboard test) $(r=0.86)$, time elapsed in $10 \mathrm{~m}$ test at comfortable or maximum speeds $(\mathrm{r}=-0.83$ and $\mathrm{r}=-0.75)$, and SF-12 physical component $(\mathrm{r}=-0.40)$.

Strengths and Weaknesses. DSI-ARSACS is the only disease-specific scale available for ARSACS. Clinimetric parameters have been insufficiently assessed.

Conclusions. DSI-ARSCAS is "listed" for the assessment of patients with ARSACS because it has been used only by its original developers.

\section{Friedreich's Ataxia Impact Scale}

Description of the Scale. The FAIS scale was developed for use in FA. ${ }^{16}$ The scale is self-administered. Although there is no record of time taken to complete the scale, the number of items (ie, 65) suggests that fatigue might be an issue. The scale is available from the original publication, and there is no copyright for use.

Clinimetric Properties. There are no data on missingness, floor or ceiling effects, or reliability. FAIS 
PEREZ LLORET E T A L

TABLE 1. Characteristics of the ataxia rating scales and functional tests included in this revision

\begin{tabular}{|c|c|c|c|c|c|c|c|}
\hline Instrument Name & $\begin{array}{l}\text { Original Target } \\
\text { Population }\end{array}$ & $\begin{array}{l}\text { Cerebellar Motor } \\
\text { Symptoms Assessed }\end{array}$ & $\begin{array}{l}\text { Functional Motor } \\
\text { Tests Used }\end{array}$ & $\begin{array}{c}\text { Other } \\
\text { Assessments }\end{array}$ & $\begin{array}{l}\text { Time Frame } \\
\text { Considered for } \\
\text { Assessment }\end{array}$ & Rater & $\begin{array}{l}\text { Direction of } \\
\text { Severity }\end{array}$ \\
\hline $\begin{array}{l}\text { Brief Ataxia Rating } \\
\text { Scale (BARS) }\end{array}$ & $\begin{array}{c}\text { All cerebellar } \\
\text { disorders }\end{array}$ & $\begin{array}{l}\text { Walking capacity, } \\
\text { upper and lower } \\
\text { limb kinetic } \\
\text { function, speech } \\
\text { clarity, and ocular } \\
\text { pursuit }\end{array}$ & None & None & $\begin{array}{l}\text { Time of } \\
\text { assessment }\end{array}$ & $\mathrm{HCP}$ & Higher values \\
\hline $\begin{array}{l}\text { Disease Severity } \\
\text { Index for } \\
\text { ARSACS (DSI- } \\
\text { ARSACS) }^{15}\end{array}$ & ARSACS & $\begin{array}{l}\text { Speech, finger to nose } \\
\text { test, circle with a } \\
\text { foot, mobility, } \\
\text { Archimedes spiral }\end{array}$ & None & $\begin{array}{l}\text { Muscle tone, } \\
\text { bladder } \\
\text { function, lateral } \\
\text { malleolus } \\
\text { vibration }\end{array}$ & $\begin{array}{l}\text { Time of } \\
\text { assessment }\end{array}$ & $\begin{array}{c}\text { HCP and } \\
\text { PtS }\end{array}$ & Higher values \\
\hline $\begin{array}{l}\text { Friedreich's Ataxia } \\
\text { Impact Scale } \\
(\text { FAIS })^{16}\end{array}$ & FA & $\begin{array}{r}\text { Speech, body } \\
\text { movement }\end{array}$ & None & $\begin{array}{l}\text { Physical } \\
\text { functioning and } \\
\text { psychological } \\
\text { and social } \\
\text { sequelae }\end{array}$ & $N / R$ & PtS & Higher values \\
\hline $\begin{array}{l}\text { Friedreich's Ataxia } \\
\text { Rating Scale } \\
(\text { FARS })^{18}\end{array}$ & FA & $\begin{array}{l}\text { Bulbar, upper and } \\
\text { lower limbs } \\
\text { coordination, } \\
\text { peripheral nervous } \\
\text { system, and } \\
\text { upright/gait } \\
\text { functions }\end{array}$ & $\begin{array}{l}\text { PATA rate, } 9 \text {-hole } \\
\text { pegboard test, } \\
\text { timed } 25 \text {-foot } \\
\text { walk test }\end{array}$ & $\begin{array}{c}\text { Functional staging } \\
\text { of mobility and } \\
\text { activities of } \\
\text { daily living }\end{array}$ & $\begin{array}{l}\text { Time of } \\
\text { assessment }\end{array}$ & $\mathrm{HCP}$ & Higher values \\
\hline $\begin{array}{l}\text { International } \\
\text { Cooperative } \\
\text { Ataxia Rating } \\
\text { Scale (ICARS) }\end{array}$ & $\begin{array}{c}\text { All cerebellar } \\
\text { diseases }\end{array}$ & $\begin{array}{l}\text { Posture and gait, limb } \\
\text { kinetic function, } \\
\text { speech disorders, } \\
\text { oculomotor } \\
\text { disorders, } \\
\text { Archimedes spiral }\end{array}$ & None & None & $\begin{array}{l}\text { Time of } \\
\text { assessment }\end{array}$ & $\mathrm{HCP}$ & Higher values \\
\hline $\begin{array}{l}\text { Fragile } X- \\
\text { associated } \\
\text { Tremor Ataxia } \\
\text { Syndrome } \\
\text { Rating Scale } \\
\text { (FXTAS-RS) }^{32}\end{array}$ & FXTAS & $\begin{array}{l}\text { Posture and stance, } \\
\text { limb movement, } \\
\text { speech, oculomotor, } \\
\text { tremor, postural } \\
\text { stability, gait, } \\
\text { handwriting, } \\
\text { Archimedes spiral }\end{array}$ & None & $\begin{array}{c}\text { Facial expression, } \\
\text { bradykinesia, } \\
\text { dystonia }\end{array}$ & $\begin{array}{l}\text { Time of } \\
\text { assessment }\end{array}$ & $\mathrm{HCP}$ & Higher values \\
\hline $\begin{array}{l}\text { Scale for the } \\
\text { Assessment and } \\
\text { Rating of Ataxia } \\
\text { (SARA) })^{56}\end{array}$ & $\begin{array}{c}\text { All cerebellar } \\
\text { diseases }\end{array}$ & $\begin{array}{l}\text { Gait, stance, sitting, } \\
\text { speech disturbance, } \\
\text { finger chase, nose } \\
\text { to finger test, fast } \\
\text { alternating hand } \\
\text { movements, heel- } \\
\text { shin slide, limb } \\
\text { kinetic function }\end{array}$ & None & None & $\begin{array}{l}\text { Time of } \\
\text { assessment }\end{array}$ & $\mathrm{HCP}$ & Higher values \\
\hline
\end{tabular}


TABLE 1. Continued

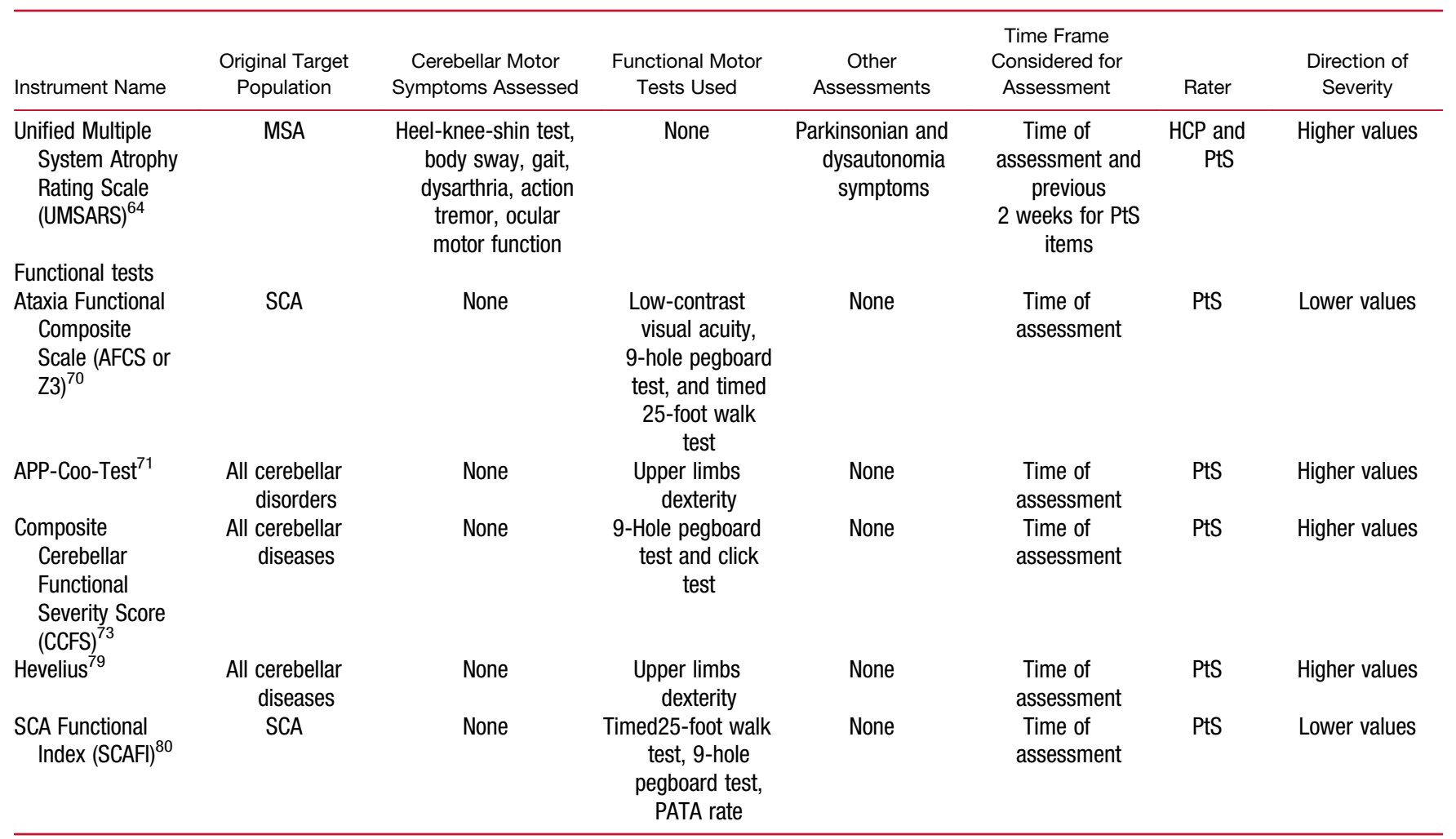

Abbreviations: ARSACS, autosomal recessive spastic ataxia of Charlevoix-Saguenay; HCP, health care professional; PtS, patient self-assessment; FA, Friedreich's ataxia; N/R, not reported; SCA, spinocerebellar ataxia; MSA, multiple system atrophy; FXTAS, fragile X-associated tremor ataxia syndrome.

subscales on symptoms and physical functioning, but not psychosocial impact, correlated with FARS score and disease duration. ${ }^{17}$ All subscales correlated with the SF36 mental and physical component summary scores. ${ }^{17}$ In a 2-year natural history study, only the speech subscale showed significant changes, thus suggesting poor responsiveness. ${ }^{17}$

Strengths and Weaknesses. FAIS is a patientreported outcome scale and, as such, provides useful additional insights into the health status and impact of patients with FA. It correlates with various relevant disease measures. The primary limitations include length, limited use, lack of validation data, and probably limited responsiveness.

Conclusions. FAIS is "suggested" for the assessment of patients with FA because the scale has been used by groups other than the developer, but adequate assessment of clinimetric properties has not been performed.

\section{Friedreich's Ataxia Rating Scale}

Description of the Scale. Friedreich's Ataxia Rating Scale (FARS) was created to fill the gap of diseasespecific ataxia rating scales to be used in FA. It was developed from a more extended scale by the
Cooperative Ataxia Group, to evaluate functional and neurological deficits with higher weight given to stance and gait items. ${ }^{18}$ It assesses bulbar symptoms, upper and lower limb coordination, peripheral nervous system, and upright/gait functions (by neurological examination). Although mainly a rating scale, the FARS also includes functional tests (PATA rate, 9HPT, and timed 25 -foot walk test [T25FW]). Finally, it includes the functional staging of mobility and activities of daily living. Scores for subsections are I $=6$, II $=36, \mathrm{III}=117$, and IV $=$ sum of times taken to perform the tests. Many authors refer to FARS Part III score as the FARS score, FARS neurological score, or FARS-n. An expanded FARS score has been defined as the sum of parts I, II, and III, with a total possible score of $159 .{ }^{19}$ A neurological score excluding facial atrophy and tongue atrophy from the bulbar subscore and the peripheral nervous system subscore is also available, it is called modified FARS (mFARS), and its total score is 93 points. $^{20}$

Clinimetric Properties. Ceiling effects were found in advanced cases. ${ }^{21}$ Conversely, the mFARS had no floor or ceiling effects. ${ }^{20}$ Studies on dimensionality of FARS have revealed conflicting results. ${ }^{18,20,22}$ Conversely, the mFARS showed four clinically meaningful factors 
PEREZ LLOR E T ET A L

TABLE 2. Summary of ataxia rating scales and functional tests clinimetric properties

\begin{tabular}{|c|c|c|c|c|c|}
\hline & Feasibility & Acceptability & Internal Consistency & Reproducibility & Interpretability \\
\hline \multicolumn{6}{|l|}{ Rating scales } \\
\hline BARS & + & 0 & + & + & 0 \\
\hline DSI-ARSACS & + & $+1-$ & + & 0 & 0 \\
\hline FAIS & $+/-$ & 0 & 0 & 0 & 0 \\
\hline FARS & + & + & + & + & 0 \\
\hline FXTAS-RS & + & 0 & 0 & 0 & 0 \\
\hline ICARS & + & + & + & + & 0 \\
\hline NESSCA & + & + & + & $+/-$ & 0 \\
\hline SARA & + & + & + & + & $+^{a}$ \\
\hline UMSARS & + & + & + & + & 0 \\
\hline \multicolumn{6}{|l|}{ Functional tests } \\
\hline AFCS & + & + & + & + & 0 \\
\hline APP-Coo-Test & + & $+/-$ & $\mathrm{N} / \mathrm{A}$ & + & 0 \\
\hline CCFS & + & + & + & + & $t^{\mathrm{b}}$ \\
\hline Hevelius & + & 0 & 0 & 0 & 0 \\
\hline SCAFI & + & + & + & + & - \\
\hline
\end{tabular}

Evidence assessment: +, adequate evaluation; +/-, adequate but incomplete evaluation, mixture of adequate and inadequate findings, or sample size was considered insufficient; -, negative evaluation; 0 , no data available.

Abbreviations: BARS, Brief Ataxia Rating Scale; DSI-ARSCAS, Disease Severity Index for Adults with Autosomal Recessive Spastic Ataxia of Charlevoix-Saguenay; FAIS, Friedreich's Ataxia Impact Scale; FARS, Friedreich's Ataxia Rating Scale; FXTAS-RS, Fragile X-associated Tremor Ataxia Syndrome Rating Scale; ICARS, International Cooperative Ataxia Rating Scale; NESSCA, Neurological Examination Score for Spinocerebellar Ataxia; SARA, Scale for the Assessment and Rating of Ataxia; UMSARS, Unified Multiple System Atrophy Rating Scale; AFCS, Ataxia Functional Composite Scale; N/A, not applicable; CCFS, Composite Cerebellar Functional Severity Score; SCAFI, SCA Functional Index.

apatients with SCA1, SCA2, SCA3, or SCA6.

bPatients with SCA3.

TABLE 3. Convergent construct validity of ataxia rating scales and functional tests by disease

\begin{tabular}{|c|c|c|c|c|c|c|c|c|c|c|c|}
\hline & SCA & FA & AT & BT & FXTAS & MSA & MS & CDG-PMM2 & NPC & ST & ARSACS \\
\hline \multicolumn{12}{|l|}{ Rating scales } \\
\hline BARS & $t^{\mathrm{a}}$ & 0 & + & + & 0 & 0 & 0 & 0 & 0 & 0 & 0 \\
\hline DSI-ARSACS & 0 & 0 & 0 & 0 & 0 & 0 & 0 & 0 & 0 & 0 & + \\
\hline FAIS & 0 & $+1-$ & 0 & 0 & 0 & 0 & 0 & 0 & 0 & 0 & 0 \\
\hline FARS & 0 & + & 0 & 0 & 0 & 0 & 0 & 0 & 0 & 0 & 0 \\
\hline FXTAS-RS & 0 & 0 & 0 & 0 & $+/-$ & 0 & 0 & 0 & 0 & 0 & 0 \\
\hline ICARS & $t^{\mathrm{b}, \mathrm{c}}$ & + & + & 0 & 0 & + & + & + & 0 & 0 & 0 \\
\hline NESSCA & $+^{\mathrm{a}, \mathrm{c}, \mathrm{d}}$ & 0 & 0 & 0 & 0 & 0 & 0 & 0 & 0 & 0 & 0 \\
\hline SARA & $++^{\mathrm{b}, \mathrm{c}}$ & + & + & + & 0 & $+/-$ & 0 & 0 & $+/-$ & + & 0 \\
\hline UMSARS & $+^{\mathrm{C}}$ & 0 & 0 & 0 & 0 & + & 0 & 0 & 0 & 0 & 0 \\
\hline \multicolumn{12}{|l|}{ Functional tests } \\
\hline AFCS & $+^{\mathrm{a}, \mathrm{d}, \mathrm{e}}$ & + & 0 & 0 & 0 & 0 & 0 & 0 & 0 & 0 & 0 \\
\hline APP-Coo-Test & 0 & + & 0 & 0 & 0 & 0 & 0 & 0 & 0 & 0 & 0 \\
\hline CCFS & $t^{a, b}$ & + & 0 & 0 & 0 & 0 & 0 & 0 & 0 & 0 & 0 \\
\hline Hevelius & 0 & 0 & 0 & 0 & 0 & 0 & 0 & 0 & 0 & 0 & 0 \\
\hline SCAFI & $+^{a, b, d}$ & $+1-$ & 0 & 0 & 0 & 0 & 0 & 0 & 0 & 0 & 0 \\
\hline
\end{tabular}

Evidence assessment: +, adequate evaluation; +/-, adequate but incomplete evaluation, mixture of adequate and inadequate findings, or sample size was considered insufficient; -, negative evaluation; 0 , no data available.

Abbreviations: SCA, spinocerebellar ataxia; FA, Friedreich's ataxia; AT, ataxia telangiectasia; BT, brain tumors; FXTAS, fragile X-associated tremor ataxia syndrome; MSA, multiple system atrophy (only the cerebellar component was considered); MS, multiple sclerosis with ataxic symptoms; CDG-PMM2, congenital disorder of glycosylation-phosphomannomutase-2 deficiency; NPC, Niemann-Pick type C; ST, stroke; ARSACS, autosomal recessive spastic ataxia of Charlevoix-Saguenay; BARS, Brief Ataxia Rating Scale; DSI-ARSCAS, Disease Severity Index for Adults with Autosomal Recessive Spastic Ataxia of CharlevoixSaguenay; FAIS, Friedreich's Ataxia Impact Scale; FARS, Friedreich's Ataxia Rating Scale; FXTAS-RS, Fragile X-associated Tremor Ataxia Syndrome Rating Scale; ICARS, International Cooperative Ataxia Rating Scale; NESSCA, Neurological Examination Score for Spinocerebellar Ataxia; SARA, Scale for the Assessment and Rating of Ataxia; UMSARS, Unified Multiple System Atrophy Rating Scale; AFCS, Ataxia Functional Composite Scale; CCFS, Composite Cerebellar Functional Severity Score; SCAFI, SCA Functional Index.

asCA7.

'SCA1, SCA2, SCA3, and SCA6.

'SCA3.

${ }^{\mathrm{d} S C A} 2$.

eSCA6. 
TABLE 4. Recommendations for ataxia rating scales and functional tests

\begin{tabular}{|c|c|c|c|c|}
\hline & $\begin{array}{l}\text { Used by Multiple } \\
\text { Groups }\end{array}$ & $\begin{array}{l}\text { F-A- } \\
I^{-a}\end{array}$ & Adequate Validity & Recommendation (Condition) \\
\hline \multicolumn{5}{|l|}{ Rating scales } \\
\hline BARS & Yes & $+/-$ & SCA, AT, BT & "Suggested" for SCA, AT, and BT \\
\hline DSI-ARSACS & No & $+/-$ & ARSACS & "Listed" \\
\hline FAIS & Yes & - & $\mathrm{FA}(+/-)$ & "Suggested" for FA \\
\hline FARS & Yes & + & FA & "Recommended" for FA \\
\hline FXTAS-RS & Yes & - & FXTAS (+/-) & "Suggested" for FXTAS \\
\hline ICARS & Yes & + & $\begin{array}{l}\text { SCA, FA, AT, MSA-C, MS, CDG-PMM2, } \\
\text { FXTAS }\end{array}$ & $\begin{array}{l}\text { "Recommended" for SCA, FA, AT, MSA-C, MS, CDG- } \\
\text { PMM2, and FXTAS }\end{array}$ \\
\hline NESSCA & Yes & $+/-$ & SCA & "Suggested" for SCA \\
\hline SARA & Yes & + & SCA, FA, AT, ST, BT & "Recommended" for SCA, FA, AT, ST, and BT \\
\hline UMSARS & Yes & + & SCA, MSA-C & "Recommended" for MSA-C \\
\hline \multicolumn{5}{|l|}{ Functional tests } \\
\hline AFCS & Yes & + & SCA, FA & "Recommended" for SCA and FA \\
\hline APP-Coo-Test & No & $+/-$ & FA & "Listed" \\
\hline CCFS & Yes & + & SCA, FA & "Recommended" for SCA and FA \\
\hline Hevelius & No & - & - & "Listed" \\
\hline SCAFI & Yes & + & SCA & "Recommended" for SCA \\
\hline
\end{tabular}

${ }^{a}$ F-A-I-R assessment (feasibility, acceptability, item scaling, and reliability): +, positive findings in all parameters; +/-, adequate but incomplete evaluation or a mixture of positive and negative results in most of the parameters; -, inadequate evaluation or relevant assessments were not performed.

Abbreviations: BARS, Brief Ataxia Rating Scale; SCA, spinocerebellar ataxia; AT, ataxia telangiectasia; BT, children with brain tumors; DSI-ARSCAS, Disease Severity Index for Adults with Autosomal Recessive Spastic Ataxia of Charlevoix-Saguenay; ARSACS, autosomal recessive spastic ataxia of Charlevoix-Saguenay; FAIS, Friedreich's Ataxia Impact Scale; FA, Friedreich's ataxia; FARS, Friedreich's Ataxia Rating Scale; FXTAS-RS, Fragile X-associated Tremor Ataxia Syndrome Rating Scale; FXTAS, fragile X-associated tremor ataxia syndrome; ICARS, International Cooperative Ataxia Rating Scale; MSA-C, multiple system atrophy (only the cerebellar component was considered); MS, multiple sclerosis with ataxic symptoms; CDG-PMM2, congenital disorder of glycosylationphosphomannomutase-2 deficiency; NESSCA, Neurological Examination Score for Spinocerebellar Ataxia; SARA, Scale for the Assessment and Rating of Ataxia; ST, cerebellar stroke; UMSARS, Unified Multiple System Atrophy Rating Scale; AFCS, Ataxia Functional Composite Scale; CCFS, Composite Cerebellar Functional Severity Score; SCAFI, SCA Functional Index.

explaining $>70 \%$ of variance. ${ }^{20}$ Internal consistency, interrater, and test-retest reliability are good. ${ }^{18,20}$ FARS scores correlated with ICARS $(\mathrm{r}=0.96),{ }^{23}$ SARA $(\mathrm{r}=0.94),{ }^{24}$ and AFCS $(\mathrm{r}=-0.92) .{ }^{25}$ The activities of daily living item of FARS correlated significantly with SARA, SCAFI, and INAS. ${ }^{26,27}$ FARS scores correlated with the modified version of Barthel index and the Functional Independence measure, ${ }^{23}$ as well as with several scales of health-related quality of life. ${ }^{22,25-27}$ Interestingly, neuroimaging studies suggest a correlation between cerebellar and spinal atrophy and FARS scores. ${ }^{28-31}$ Responsiveness statistics are shown in Supporting Information Table E-1 in AppendixS1.

Strengths and Weaknesses. FARS captures multiple domains of the disease and is frequently used in clinical practice, observational studies, and clinical trials. Ceiling effect is the main limitation, thus precluding use in severely affected patients. It has been suggested that using FARS-n or the mFARS might overcome this issue.

Conclusions. FARS is "recommended" for the assessment of patients with FA. The scale has been used by groups other than the developer, and its use is supported by adequate clinimetric data.

\section{Fragile X-Associated Tremor Ataxia Syndrome Rating Scale}

Description of the Scale. The FTAX-RS was developed for the assessment of the severity of most significant motor signs of fragile $\mathrm{X}$-associated tremor ataxia syndrome (FXTAS). ${ }^{32} \mathrm{~A}$ shorter version of the scale is also available and known as mFTAX-RS. ${ }^{33}$

Clinimetric Properties. Information on missingness, floor and ceiling effects, and dimensionality are not available. Similarly, there is no information on internal consistency or reliability. Validity has been insufficiently studied. Some studies show that FXTAS-RS scores are higher in patients than in controls or premutation carriers without the disease. ${ }^{34,35}$ FXTAS-RS correlated with stride length and velocity variability, the Berg Balance Scale, and Functional Independence Measure. ${ }^{36}$ A correlation between this score and CGG repeat length of the FMR1 gene has been observed in some studies, ${ }^{32,36}$ but not in others. ${ }^{34}$ Finally, age also correlated strongly with the worsening of FXTAS-RS scores. ${ }^{32}$ Responsiveness has not been studied.

Strengths and Weaknesses. FXTAS-RS is the only available disease-specific rating scale for FXTAS. Assessment of clinimetric properties is incomplete. 
PEREZ LLORET ET A L

Conclusions. FXTAS-RS is "suggested" for the assessment of patients with FXTAS. The scale has been used by groups other than the developer, but its clinimetric properties have been poorly studied.

\section{International Cooperative Ataxia Rating Scale}

Description of the Scale. ICARS was developed because of the necessity of a standard tool to evaluate cerebellar ataxia that could be used to test treatment efficacy in randomized clinical trials during the 1990s. ${ }^{3}$ The scale has 19 items and four theoretical subscales domains: posture and gait, limb kinetic function, speech disorders, and oculomotor disorders. ${ }^{3}$ The scale is in the public domain and can be obtained from the original publication. ${ }^{3}$ Time to administer ICARS varied from 12 to 21 minutes. ${ }^{37}$

Clinimetric Properties. Ceiling and floor effects have been observed in $6 \%$ and $10 \%$ of patients with FA. ${ }^{24,38,39}$ The posture and gait and kinetic function subscales showed considerable ceiling effect. ${ }^{39}$ Furthermore, 9 of 19 items reached their maximum score for $>50 \%$ of patients with an ICARS $>60$, showing a plateau effect in more severely affected patients. ${ }^{39}$ There is no information on missing data, but this is one of the most frequently used scales and is evaluated by a health care professional, which suggests that this may not be a problem. Dimensionality in the ICARS has been studied in many conditions, including multiple system atrophy (MSA), SCA, FA, and multiple sclerosis (MS) with ataxic symptoms. ${ }^{24,37,39-42}$ Internal consistency was greater than 0.90 in MSA, SCA, FA, and MS with ataxic symptoms, ${ }^{37-39,41-44}$ and 0.72 in congenital disorder of glycosylation-phosphomannomutase- 2 deficiency (CDG-PMM2). ${ }^{45}$ Interrater and intrarater reliability could be demonstrated for SCA, ${ }^{37}$ CDGPMM2, ${ }^{45} \mathrm{FA},{ }^{38,46} \mathrm{MS}$ with ataxic symptoms, ${ }^{42}$ and focal cerebellar lesions. ${ }^{41}$ Many studies have assessed the validity of ICARS. In FA, ICARS correlated significantly with FARS $(r=0.96)$ and with disease duration. $^{23,24}$ In AT, it correlated with BARS $(r=0.93)$, SARA ( $\mathrm{r}=0.83$ ), and a Clinical Global Impression scale for AT $(r=0.76) .{ }^{13}$ In individuals with CDG-PMM2, ICARS correlated with the Nijmegen Pediatric CDG Rating Scale $(r=0.90),{ }^{45}$ while the total and speech scores also correlated with the PATA rate. ${ }^{47}$ In SCA, ICARS correlated with Barthel index $(r=-0.70)$ and disease duration. ${ }^{37}$ Other data also suggest validity in MSA, ${ }^{40}$ MS with ataxic symptoms, ${ }^{42}$ and FXTAS. ${ }^{48}$ ICARS was also related to brain atrophy as measured by neuroimaging techniques. ${ }^{49-52}$ Responsiveness statistics are shown in Supporting Information Table E-1 in Appendix S1.

Strengths and Weaknesses. ICARS is one of the first ataxia rating scales and has been widely used.
Robust evidence supports its use in many cerebellar disorders. Notwithstanding, the scale has some limitations, including some redundancy in items and a plateau in patients with long disease duration.

Conclusions. ICARS is "recommended" for the assessment of cerebellar symptoms severity in SCA, FA, AT, MSA-C (MSA cerebellar component), FXTAS, MS with ataxic symptoms, and CDG-PMM2. It has been used by groups other than the developer, and its use is supported by adequate clinimetric data.

\section{Neurological Examination Score for Spinocerebellar Ataxia}

Description of the Scale. NESSCA was developed as a global and comprehensive inventory for the assessment of SCA, targeting ataxia and nonataxia signs. ${ }^{53}$ The time for completion is about 30 minutes. The scale is available on the original publication, and there is no copyright.

Clinimetric Properties. No floor and ceiling effects have been observed. ${ }^{53,54}$ There is no information on missing data, but the use of the scale in many clinical trials and studies suggests that this may be a minor issue. Internal consistency was adequate, with a Cronbach's alpha of $0.77 .^{53}$ Interrater reliability was high ${ }^{53}$ but there are no data on test-retest reliability. In patients with SCA3, NESSCA correlated significantly with SARA $(r=0.86)$ and Barthel functional disability index $(\mathrm{r}=-0.44) .{ }^{53}$ In patients with SCA2, NESSCA correlated with SARA $(\mathrm{r}=0.62) .{ }^{54}$ NESSCA score was significantly higher in patients with SCA7 compared with control subjects or unaffected mutation carriers. ${ }^{55}$ Responsiveness statistics are shown in Supporting Information Table E-1 in Appendix S1.

Strengths and Weaknesses. NESSCA can be easily assessed by a neurologist in 30 minutes, mixing objective and subjective items. Assessment of test-retest has not been performed yet. The prolonged progression of extracerebellar symptoms and signs impacts on the responsiveness of this scale.

Conclusions. NESSCA is "suggested" for the assessment of patients with SCA because it has been used by groups other than the developer, but clinimetric assessment is not complete.

\section{Scale for the Assessment and Rating of Ataxia}

Description of the Scale. SARA was developed as a reliable and valid clinical scale measuring the severity of ataxia to be used in all cerebellar disorders. ${ }^{56}$ It is one of the most widely used ataxia rating scales. SARA has eight items that yield a total score of 0 (no ataxia) to 40 (most severe ataxia), assessing gait, stance, sitting, 
speech disturbance, finger chase, nose to finger test, fast alternating hand movements, and heel-shin slide. For the last five items, the arithmetic mean of both sides should be computed. Time for completion by a trained health care professional is less than 15 minutes in most cases. The scale is in the public domain and can be downloaded from: http://www.ataxia-study-group.net/ html/about/ataxiascales/sara/SARA.pdf.

Clinimetric Properties. No floor and ceiling effects for the total score were observed. Conversely, some items, such as sitting, may display ceiling effects. ${ }^{24,56,57}$ Data missingness is not available, but the wide use of the scale suggests that this may not be an issue. Confirmatory factor analysis revealed a single underlying factor. $^{24,56,58}$ Internal consistency, interrater reliability, and test-retest reliability were high. ${ }^{12,24,56-59}$ Regarding validity, the rate of change in SARA scores correlated with atrophy rate of the cerebellum $(\mathrm{r}=-0.81) .{ }^{60}$ SARA subscores correlated with volumes of the brain stem, cerebellar vermis, and cerebellar hemispheres. ${ }^{61}$ In patients with SCA, SARA correlated with the Barthel index $(\mathrm{r}=-0.80)$ and the functional component of the Unified Huntington's System Atrophy Rating Scale (UHDRS). ${ }^{56}$ A correlation with disease duration has also been observed. ${ }^{62}$ SARA score was significantly higher in patients with SCA7 compared with controls or preclinical mutation carriers. ${ }^{55}$ In FA, SARA scores were significantly correlated to ICARS $(\mathrm{r}=0.95)$ and FARS $(r=0.94) .{ }^{24}$ SARA was also correlated with measures of disease severity in other diseases, such as mild cerebellar stroke, ${ }^{63}$ children with $\mathrm{BTs},{ }^{12}$ and $\mathrm{AT}^{13}$ Responsiveness statistics are shown in Supporting Information Table E-1 in Appendix S1. The smallest detectable change for intraindividual score differences was $<3.5 .^{57}$

Strengths and Weaknesses. SARA is a reliable and valid semiquantitative rating scale of ataxia that requires only 15 minutes for completion. SARA has less repetitive items, is less time-consuming to administer, and is easier to use than ICARS. The primary limitations include the absence of functional tests and lack of assessment of nonataxia symptoms, thus suggesting that it should be complemented with other scales. Furthermore, the findings of a significant proportion of abnormal results in controls (kinetic functions of the nondominant side) suggests that it may not be an ideal tool for disease screening. Use in children younger than 12 years has been discouraged by some authors. ${ }^{11}$

Conclusions. SARA is "recommended" for assessment of cerebellar symptoms in SCA, FA, AT, cerebellar stroke, and children with BT. The scale has been used by groups other than the developer, and its use is supported by adequate clinimetric data.

\section{Unified Multiple System Atrophy Rating Scale}

Description of the Scale. MSA is a degenerative disorder of the central and autonomic nervous systems characterized by parkinsonian, cerebellar, and autonomic symptoms. ${ }^{64}$ The completion time is about 30 to 45 minutes. Part II (motor examination) should be done by a trained health care professional. The scale is owned by the MDS and can be accessed online (https:// www.movementdisorders.org/MDS/MDS-Rating-Scales/ Unified-Multiple-System-Atrophy-Rating-Scale-UMSARS. $\mathrm{htm})$. Here, we will assess the performance of UMSARSII (motor score) only in patients with MSA with predominant cerebellar ataxia (ie, MSA-C subtype) or other cerebellar disorders.

Clinimetric Properties. No floor or ceiling effects were observed in patients with SCA3. ${ }^{43}$ Data missingness has not been formally assessed by the frequent use of this scale in observational studies, and clinical trials suggest that this may not be an issue. Cronbach's alpha coefficient of UMSARS-II was 0.90, and most items showed a high item-to-total correlation. ${ }^{65}$ Interrater reliability was high for UMSARS-II total score and at least substantial for most of the scale's items. $^{65,66}$ The test-retest reliability of UMSARS Parts I, II, and IV, calculated from a sample of 30 patients assessed twice in a 30-day period in the same condition, ${ }^{67}$ was adequate (all Intraclass Correlation Coefficients (ICCs) > 0.84). Regarding validity, in patients with MSA-C, UMSARS-II correlated with loss of connectivity in the thalamus and cerebellum $(P<0.05){ }^{68}$ UMSARS-II correlated with ICARS in patients with MSA $(r=0.93)^{65}$ or SCA3 $(r=0.96) .{ }^{43}$ Higher UMSARS scores were significant predictors of loss of independent walking and wheelchair use in patients with MSA-C. ${ }^{69}$ Responsiveness statistics are shown in Supporting Information Table E-1 in Appendix S1, indicating that the scale can adequately record changes in MSA.

Strengths and Weaknesses. UMSARS is the only disease-specific scale for MSA. Robust evidence supports its use for the assessment of cerebellar and noncerebellar symptoms in MSA.

Conclusions. UMSARS is "recommended" for the assessment of cerebellar symptoms in MSA because it has been used by groups other than the developer and its use is supported by adequate clinimetric data. The scale was developed for and validated in patients with MSA; therefore, it cannot be recommended for use in patients with SCA. 


\section{Functional Tests}

Ataxia Functional Composite Scale

Description of the Scale. AFCS was developed to provide a sensitive and reproducible assessment of treatment responses in studies of the SCAs based on functional tests, extending results obtained in $\mathrm{MS}^{70}$ The AFCS is a composite of the $z$ scores of three wellknown functional tests: low-contrast visual acuity, 9HPT, and T25FW. ${ }^{70}$ Tests are widely accessible, and there is no copyright for use. It takes about 20 minutes to complete all evaluations.

Clinimetric Properties. A significant proportion of patients with FA, especially the more severe ones, were not able to complete all tests. ${ }^{22}$ High internal consistency and test-retest reliability have been observed in FA. ${ }^{22}$ A significant correlation was observed between ICARS and AFCS in patients with SCA. ${ }^{70}$ In FA, AFCS correlated significantly with FARS $(\mathrm{r}=-0.92) .{ }^{22,25}$ Responsiveness statistics are shown in Supporting Information Table E-1 in Appendix S1.

Strengths and Weaknesses. AFCS is an easy-tocomplete set of functional tests with good validity, test-retest reliability, and responsiveness. The main limitation is that patients at the more severe end of the spectrum may not be able to complete all tests.

Conclusions. AFCS is "recommended" for the assessment of functional performance in patients with SCA and FA. It has been used by groups other than the developer, and its use is supported by adequate clinimetric data.

\section{APP-Coo-Test}

Description of the Scale. The authors aimed at developing an easy-to-perform test that could be used in an advanced state of cerebellar diseases, which may be difficult with other functional tests. ${ }^{71}$ The 15 -White Dots APP-Coo-Test is a free app that can be downloaded for iOS or Android operating systems. It was developed based on other existing functional tests (eg, 9HPT). Patients are instructed to press with their index finger on the 15 white dots that will appear on the screen sequentially in random positions. The quantitative measurement of each upper limb movement is the motion execution time. A version with 12 red squares was used in a study with patients with FA. ${ }^{72}$

Clinimetric Properties. In a mixed population of patients with cerebellar disorders, execution times correlated significantly with 9HPT $(\mathrm{r}=0.81)$, click test $(r=0.90)$, SARA $(r=0.85)$, and CCFS $(r=0.89) .{ }^{71} \mathrm{In}$ patients with FA, a modified version of the test correlated with disease duration $(\mathrm{r}=0.44, P<0.02)$, 9HPT $(r=0.72)$, click test $(r=0.83)$, CCFS $(r=0.87)$, SARA total score $(\mathrm{r}=0.77)$, and SARA items 5,6 , and 7 $(\mathrm{r}=0.81) .{ }^{72}$ Regarding precision, the mean detectable change was 0.482 in the mixed sample of cerebellar disorders and 0.23 in FA. ${ }^{71,72}$ Regarding responsiveness, $95 \%$ minimal detectable change (MDC) was $0.482,{ }^{71}$ and for the Twelve-Red-Squares App-Coo-Test was $0.23 .^{72}$

Strengths and Weaknesses. The APP-Coo-Test is faster and easier to use than most functional tests used in ataxia. It is free and runs on any mobile phone or tablet. Its use is not supported by adequate clinimetric use.

Conclusions. The APP-Coo-Test is "listed" for the assessment of the functional performance because it has been used only by its original developers.

\section{Composite Cerebellar Functional Severity Score}

Description of the Scale. The CCFS was developed as a single composite functional score for assessing cerebellar ataxia in the upper limbs over a wide range of severity. ${ }^{73}$ The CCFS total score is calculated as a combination of the time to perform the 9HPT and the click test (ie, the time taken by a patient to press alternatively on two counters placed $39 \mathrm{~cm}$ apart for 10 times) and is corrected for responders' age, thus allowing for age group comparisons. ${ }^{73}$ It takes less than 5 minutes to complete both tests. There is no copyright, and a full description of tests and formulas for obtaining the final score can be found in the original publication. ${ }^{73}$

Clinimetric Properties. As in the case of AFCS, not all patients may be able to complete all tests, especially the most severely affected ones. ${ }^{74}$ Test-retest reliability was good in healthy individuals. ${ }^{75}$ Pegboard and click scores correlated significantly between each other $(\mathrm{r}=0.74) .{ }^{73}$ CCFS correlated significantly with UHDRS-IV disability score $(\mathrm{r}=-0.78)$ and EQ-5D Visual Analog Scale score $(\mathrm{r}=-0.41)$ in patients with autosomal dominant cerebellar ataxias. ${ }^{73}$ CCFS scores were higher in control subjects than in patients with SCA and FA, and correlated significantly with SARA. ${ }^{73,74,76}$ CCFS has been shown to discriminate between patients with SCA1, SCA2, SCA3, and SCA7 (but not SCA6) and control subjects. ${ }^{55,77}$ Responsiveness statistics are shown in Supporting Information Table E-1 in Appendix S1. The responsiveness of the scale can be improved if a writing score of the dominant arm is included (ie, the CCFSw). Notwithstanding, the validity of the CCFSw has not been tested. Finally, CCFS, but not NESSCA or SCAFI, discriminated patients with SCA3 considered worse according to 
Patient Global Impression from stable/better on receiver operating characteristic curve analysis. ${ }^{78}$

Strengths and Weaknesses. CCFS is a quantitative test of upper limb ataxia that has shown adequate validity and reliability for some cerebellar disorders, independently of age. Its main limitation is the presence of ceiling effects.

Conclusions. The CCFS is "recommended" for the assessment of functional performance in SCA and FA because it has been used by groups other than the developer and its use is supported by adequate clinimetric data.

\section{Hevelius}

Description of the Scale. Hevelius was developed to complement existing assessment methods with a standardized, objective, reliable tool that could characterize motor performance in the arm across several disorders of human movement. ${ }^{79}$ Participants are instructed to use the mouse to click on a target (a red circle) on a computer screen as soon as it appears. Each evaluation takes between 2 and 6 minutes. There is no information on how to access the test.

Clinimetric Properties. Acceptability, item scaling, reliability, responsiveness, and interpretability have not been assessed. Regarding validity, parameters calculated from tests results correlated significantly with BARS total score and dominant arm score in a mixed population of patients with cerebellar disorders. ${ }^{79}$

Strengths and Weaknesses. Hevelius might represent a reliable proxy measure of arm motor function that may be used outside the clinic setting and may allow comparisons of patients with ataxia and other movement disorders. Full clinimetric evaluation is needed.

Conclusions. Hevelius is "listed" for the assessment of functional performance because it has been used only by its original developers.

\section{SCA Functional Index}

Description of the Scale. SCAFI was developed under the hypothesis that continuous quantitative data might provide higher interrater reliability than subjective clinical rating scales. ${ }^{80}$ The three tests included (T25FW, 9HPT, and PATA rate) are widely used in ataxia and other neurological conditions. The completion time is 8 minutes or less. Tests are not subjected to copyright, and their description can be found in the original publication.
Clinimetric Properties. Missing data were less than $10 \%$ in SCA and FA. ${ }^{26,80}$ Ceiling and floor effects were not present. ${ }^{57,80}$ Internal consistency was adequate. ${ }^{80}$ Test-retest reliability was good. ${ }^{57}$ In SCA1, SCA2, SCA3, and SCA6, SCAFI correlated significantly with disease duration $(\mathrm{r}=-0.41)$, SARA scores $(\mathrm{r}=-0.87)$, UHDRS-IV $(\mathrm{r}=0.81)$, and cognitive impairment $(\mathrm{r}=0.81) .{ }^{80}$ In patients with SCA2, SCAFI correlated significantly with NESSCA $(\mathrm{r}=-0.65) .{ }^{54}$ In these patient groups, SCAFI could differentiate patients from controls or nonaffected mutation carriers. ${ }^{55,77}$ In patients with FA, it correlated significantly with disease progression. ${ }^{26}$ Precision was not considered high enough. ${ }^{57}$ Responsiveness statistics are shown in Supporting Information Table E-1 in Appendix S1. SCAFI was not accurate enough to identify patients with SCA2 who worsened or not during follow-up (area under the curve of the receiver operating characteristic curve = $0.49,95 \%$ confidence interval: $0.23-0.75)$, thus failing to show interpretability. ${ }^{54}$

Strengths and Weaknesses. SCAFI offers the possibility of gathering quantitative, objective data. It is easy to perform and devoid of floor or ceiling effects. Results may be easily compared with other diseases assessed by the same tests. Interpretability may be inadequate.

Conclusions. SCAFI is "recommended" for the assessment of functional performance in SCA because it has been used by groups other than the developer and its use is supported by adequate clinimetric data.

\section{Discussion}

We reviewed the clinimetric parameters of ataxia rating scales and functional tests by using a highly standardized methodology developed by the MDS Rating Scales Committee. Results from the assessment allowed us to issue recommendations for the use of ataxia rating scales and functional tests, which will be discussed in the following subsections.

\section{Rating Scales for Ataxia}

As shown in Table 5, FARS, ${ }^{18}$ ICARS,${ }^{3}$ SARA,${ }^{56}$ and UMSARS $^{65}$ could be recommended for use in SCA, FA, and other less frequent cerebellar diseases. Regrettably, validation data are lacking for many cerebellar disorders. It is therefore mandatory that validation of rating scales be conducted in conditions for which such data are missing.

SARA and ICARS are probably the most used ataxia scales in the literature. ICARS did better than SARA in terms of responsiveness in patients with SCA or FA (see Supporting Information Table E-1 in Appendix S1), 
PEREZ LLORET ET AL

TABLE 5. "Recommended" rating scales and functional tests by cerebellar disorder

\begin{tabular}{|c|c|c|}
\hline Cerebellar Disease & Rating Scales & $\begin{array}{l}\text { Functional } \\
\text { Tests }\end{array}$ \\
\hline Ataxia telangiectasia & ICARS, SARA & - \\
\hline $\begin{array}{l}\text { Brain tumors (cerebellar } \\
\text { symptoms) }\end{array}$ & SARA & - \\
\hline $\begin{array}{l}\text { Congenital disorder of } \\
\text { glycosylation- } \\
\text { phosphomannomutase-2 } \\
\text { deficiency (cerebellar } \\
\text { symptoms) }\end{array}$ & ICARS & - \\
\hline $\begin{array}{l}\text { Fragile } X \text {-associated tremor } \\
\text { ataxia syndrome }\end{array}$ & ICARS & - \\
\hline Friedreich's ataxia & $\begin{array}{l}\text { FARS (disease specific), } \\
\text { ICARS, SARA }\end{array}$ & AFCS, CCFS \\
\hline $\begin{array}{l}\text { Multiple sclerosis with ataxia } \\
\text { symptoms }\end{array}$ & ICARS & - \\
\hline $\begin{array}{l}\text { Multiple system atrophy } \\
\text { (cerebellar symptoms) }\end{array}$ & $\begin{array}{l}\text { UMSARS (disease } \\
\text { specific), ICARS }\end{array}$ & - \\
\hline Spinocerebellar ataxia & ICARS, SARA & $\begin{array}{l}\text { AFCS, CCFS, } \\
\text { SCAFI }\end{array}$ \\
\hline Stroke (cerebellar symptoms) & SARA & - \\
\hline
\end{tabular}

Abbreviations: ICARS, International Cooperative Ataxia Rating Scale; SARA, Scale for the Assessment and Rating of Ataxia; FARS, Friedreich's Ataxia Rating Scale; AFCS, Ataxia Functional Composite Scale; CCFS, Composite Cerebellar Functional Severity Score; UMSARS, Unified Multiple System Atrophy Rating Scale; SCAFI, SCA Functional Index.

which may be the result of some redundancy in items of the former. SARA has less redundant items and may offer other advantages, including better dimensionality and better reproducibility. Its shortness could also be an advantage for patients with behavioral comorbidities or fatigue. ${ }^{81}$ We did not assess the usefulness of ataxia scales and functional tests for clinical trials because the methodological framework we used was not designed for this purpose. This is an important issue that deserves further attention.

Ceiling effects were observed for some of the most frequently used scales (ie, FARS, ICARS, and some items of the SARA), limiting their utility in patients on the more severe end of the spectrum. These patients are not easy to assess, and there is no ideal instrument that may be applied to them. Further research is warranted. A similar problem is observed in children, who may become easily fatigued after extensive testing. This is not a problem for scales that were developed for the assessment of disease that typically affects childhood, such as FA. The BARS has been successfully applied to children. ${ }^{11}$ This scale could only be "suggested" because data on acceptability were absent; thus, further research is needed. SARA has been used in children with $\mathrm{BT},{ }^{12}$ but its use in children younger than 12 years has been discouraged. ${ }^{11}$ More data are needed for the rest of the scales.

Another problematic aspect is the assessment of patients in prodromal stages of cerebellar diseases. Our results cannot be extrapolated to this context, and thus each scale should be validated in these populations of patients. This has been the case with ICARS, which has been shown to differentiate men carrying a small CGG repeat expansion (ie, premutation carriers) in the FMR1 gene compared with control subjects. ${ }^{48,82,83}$ SARA could also differentiate SCA1 and SCA2 nonaffected mutations carriers from noncarriers. ${ }^{77}$

For this review, we worked under the assumption that results on the acceptability, internal consistency, or reproducibility of a scale may not be specific for a given disease, and thus they could be applied more generically. Notwithstanding, studying these parameters in each cerebellar disorder might give more precise estimates. This task force believes that there is no need to develop more generic ataxia rating scales but recommends validation of the available ones for cerebellar disorders not covered at present.

Cerebellar disorders are a very heterogeneous group of diseases that may have many symptoms besides ataxia. $^{2,84,85}$ Therefore, whenever available, diseasespecific scales should be used to capture better all dimensions of the disease under study. Several diseasespecific scales have been developed for cerebellar disorders, including the DSI-ARSACS, FAIS, FARS, FXTASRS, NESSCA, and UMSARS. FARS is the scale of choice for the assessment of patients with FA, and UMSARS should be used for the assessment of patients with MSA. Conversely, clinimetric data for DSIARSCAS, FAIS, FXTAS-RS, and NESSCA were not strong enough to recommend them for use. NESSCA, which has been mostly used for the assessment of patients with SCA2 and SCA3, could only be "suggested" because data on test-retest reliability were not available. Further research is warranted.

Finally, the use of disease-specific scales for assessment of cerebellar disorders other than the originally targeted disease is discouraged. As mentioned earlier, these scales have been developed to cover diseasespecific dimensions, which may not be relevant for other disorders.

\section{Functional Tests}

The $\mathrm{AFCS}^{70}$ and $\mathrm{CCFS}^{73}$ could be recommended for the assessment of patients with FA, whereas both of these tests and the $\mathrm{SCAFI}^{80}$ were recommended for patients with SCA (Table 5). CCFS allows for comparisons with control populations, which is not possible with the other instruments. ${ }^{73}$

Functional tests were originally developed to obtain better reliability in the assessment of patients, which has never been demonstrated. Furthermore, they may share some of the limitations of rating scales, namely, the difficulties in evaluating patients at the more severe end of the spectrum, as observed for AFCS and CCFS. Conversely, they may be more easily applied to children 
than rating scales. Indeed, CCFS has been successfully used in children older than 7 years. ${ }^{86}$ Further research is warranted for the other instruments. Regarding the use of a functional test to differentiate nonaffected mutation carriers from control subjects, SCAFI score was lower in nonaffected SCA2 mutation carriers compared with control subjects. ${ }^{77}$ CCFS score was higher in nonaffected SCA1, SCA2, and SCA3 mutation carriers compared with control subjects. ${ }^{77}$

Some recently developed tests, such as APP-Coo-Test and Hevelius, offer the exciting possibility of measuring upper limb dexterity outside the clinical setting. ${ }^{71,79}$ These tests could complement the assessment of patients in the clinic. More validation studies are needed before the use of these tools can be recommended.

It must be noteworthy that the bibliographical search was conducted only in PubMed. This is one of the largest bibliographical databases, but including other databases might have yielded some extra references.

\section{Assessment of Nonataxia Features in Patients with Cerebellar Disorders}

In this review, we focused on the assessment of ataxia. Notwithstanding, patients with cerebellar disorders are frequently affected by other cerebellar and noncerebellar symptoms. ${ }^{2,84,85}$ Such symptoms can be assessed within disease-specific ratings scales, such as the FAIS, NESSCA, and UMSARS, or by the INAS. ${ }^{87}$ Neuropsychological and psychiatric disorders may be explored by means of the cerebellar cognitive affective/ Schmahmann syndrome scale. ${ }^{88}$

Acknowledgments: Several authors of this publication are members of the European Reference Network for Rare Neurological Diseases (Project ID No. 739510).

\section{APPENDIX}

Members of the MDS Committee on Rating Scales: Richard G. Brown, Jennifer G. Goldman, Michelle Hyczy de Siqueira Tosin, Aparna Wagle Shukla, Mayela Rodriguez Violante, and Daniel Weintraub.

\section{References}

1. Akbar U, Ashizawa T. Ataxia. Neurol Clin 2015;33:225-248.

2. Pandolfo M, Manto M. Cerebellar and afferent ataxias. Continuum (Minneap Minn) 2013;19:1312-1343.

3. Trouillas P, Takayanagi T, Hallett M, et al. International Cooperative Ataxia Rating Scale for pharmacological assessment of the cerebellar syndrome. The Ataxia Neuropharmacology Committee of the World Federation of Neurology. J Neurol Sci 1997;145:205-211.

4. Ruano L, Melo C, Silva MC, Coutinho P. The global epidemiology of hereditary ataxia and spastic paraplegia: a systematic review of prevalence studies. Neuroepidemiology 2014;42:174-183.

5. Saute JA, Donis KC, Serrano-Munuera C, et al. Ataxia rating scales-psychometric profiles, natural history and their application in clinical trials. Cerebellum 2012;11:488-504.
6. Paap BK, Roeske S, Durr A, et al. Standardized assessment of hereditary ataxia patients in clinical studies. Mov Disord Clin Pract 2016; 3:230-240.

7. Skorvanek M, Goldman JG, Jahanshahi M, et al. Global scales for cognitive screening in Parkinson's disease: critique and recommendations. Mov Disord 2018;33:208-218.

8. Martinez-Martin P, Forjaz MJ. How to evaluate validation data. In: Sampaio C, Goetz CG, Schrag A, eds. Rating Scales in Parkinson's Disease: Clinical Practice and Research. New York, NY: Oxford University Press; 2012.

9. Schmahmann JD, Gardner R, MacMore J, Vangel MG. Development of a brief ataxia rating scale (BARS) based on a modified form of the ICARS. Mov Disord 2009;24:1820-1828.

10. Camargos S, Cardoso F, Maciel R, et al. Brief ataxia rating scale: a reliable tool to rate ataxia in a short timeframe. Mov Disord Clin Pract 2016;3:621-623.

11. Brandsma R, Spits AH, Kuiper MJ, et al. Ataxia rating scales are age-dependent in healthy children. Dev Med Child Neurol 2014;56: 556-563.

12. Hartley H, Pizer B, Lane S, et al. Inter-rater reliability and validity of two ataxia rating scales in children with brain tumours. Childs Nerv Syst 2015;31:693-697.

13. Nissenkorn A, Borgohain R, Micheli R, et al. Development of global rating instruments for pediatric patients with ataxia telangiectasia. Eur J Paediatr Neurol 2016;20:140-146.

14. Velazquez-Perez L, Cerecedo-Zapata CM, Hernandez-Hernandez O, et al. A comprehensive clinical and genetic study of a large Mexican population with spinocerebellar ataxia type 7. Neurogenetics 2015; 16:11-21.

15. Gagnon C, Brais B, Lessard I, Lavoie C, Cote I, Mathieu J. Development and validation of a disease severity index for ataxia of Charlevoix-Saguenay. Neurology 2019;93:e1543-e1549.

16. Cano SJ, Riazi A, Schapira AH, Cooper JM, Hobart JC. Friedreich's ataxia impact scale: a new measure striving to provide the flexibility required by today's studies. Mov Disord 2009;24:984-992.

17. Tai G, Yiu EM, Corben LA, Delatycki MB. A longitudinal study of the Friedreich Ataxia Impact Scale. J Neurol Sci 2015;352:53-57.

18. Subramony SH, May W, Lynch D, et al. Measuring Friedreich ataxia: interrater reliability of a neurologic rating scale. Neurology 2005;64:1261-1262.

19. Friedman LS, Farmer JM, Perlman S, et al. Measuring the rate of progression in Friedreich ataxia: implications for clinical trial design. Mov Disord 2010;25:426-432.

20. Rummey C, Corben LA, Delatycki MB, et al. Psychometric properties of the Friedreich Ataxia Rating Scale. Neurol Genet 2019;5:371.

21. Regner SR, Wilcox NS, Friedman LS, et al. Friedreich ataxia clinical outcome measures: natural history evaluation in 410 participants. J Child Neurol 2012;27:1152-1158.

22. Lynch DR, Farmer JM, Tsou AY, et al. Measuring Friedreich ataxia: complementary features of examination and performance measures. Neurology 2006;66:1711-1716.

23. Fahey MC, Corben L, Collins V, Churchyard AJ, Delatycki MB. How is disease progress in Friedreich's ataxia best measured? A study of four rating scales. J Neurol Neurosurg Psychiatry 2007;78: 411-413.

24. Burk K, Malzig U, Wolf S, et al. Comparison of three clinical rating scales in Friedreich ataxia (FRDA). Mov Disord 2009;24:17791784.

25. Tai G, Yiu EM, Delatycki MB, Corben LA. How does performance of the Friedreich Ataxia Functional Composite compare to rating scales? J Neurol Neurosurg Psychiatry 2017;264:1768-1776.

26. Reetz K, Dogan I, Costa AS, et al. Biological and clinical characteristics of the European Friedreich's Ataxia Consortium for Translational Studies (EFACTS) cohort: a cross-sectional analysis of baseline data. Lancet Neurol 2015;14:174-182.

27. Reetz K, Dogan I, Hilgers RD, et al. Progression characteristics of the European Friedreich's Ataxia Consortium for Translational Studies (EFACTS): a 2 year cohort study. Lancet Neurol 2016;15: 1346-1354. 
28. Bonilha da Silva C, Bergo FPG, D'Abreu A, Cendes F, LopesCendes I, Franca MC Jr. Dentate nuclei T2 relaxometry is a reliable neuroimaging marker in Friedreich's ataxia. Eur J Neurol 2014;21: 1131-1136.

29. Clemm von Hohenberg C, Schocke MF, Wigand MC, et al. Radial diffusivity in the cerebellar peduncles correlates with clinical severity in Friedreich ataxia. Neurol Sci 2013;34:1459-1462.

30. Akhlaghi H, Corben L, Georgiou-Karistianis N, et al. Superior cerebellar peduncle atrophy in Friedreich's ataxia correlates with disease symptoms. Cerebellum 2011;10:81-87.

31. Chevis CF, da Silva CB, D'Abreu A, et al. Spinal cord atrophy correlates with disability in Friedreich's ataxia. Cerebellum 2013;12: 43-47.

32. Leehey MA, Berry-Kravis E, Goetz CG, et al. FMR1 CGG repeat length predicts motor dysfunction in premutation carriers. Neurology 2008;70:1397-1402.

33. Hall DA, Stebbins GT, Jacquemont S, et al. Clinimetric properties of the Fragile X-associated Tremor Ataxia Syndrome Rating Scale. Mov Disord Clin Pract 2019;6:120-124.

34. Hall D, Todorova-Koteva K, Pandya S, et al. Neurological and endocrine phenotypes of fragile X carrier women. Clin Genet 2016; 89:60-67.

35. Vittal P, Pandya S, Sharp K, et al. ASFMR1 splice variant: a predictor of fragile X-associated tremor/ataxia syndrome. Neurol Genet 2018;4:e246.

36. O'Keefe JA, Robertson-Dick EE, Hall DA, Berry-Kravis E. Gait and functional mobility deficits in Fragile X-Associated Tremor/Ataxia Syndrome. Cerebellum 2016;15:475-482.

37. Schmitz-Hubsch T, Tezenas du Montcel S, Baliko L, et al. Reliability and validity of the International Cooperative Ataxia Rating Scale: a study in 156 spinocerebellar ataxia patients. Mov Disord 2006;21: 699-704.

38. Cano SJ, Hobart JC, Hart PE, Korlipara LV, Schapira AH, Cooper JM. International Cooperative Ataxia Rating Scale (ICARS): appropriate for studies of Friedreich's ataxia? Mov Disord 2005;20: 1585-1591.

39. Metz G, Coppard N, Cooper JM, et al. Rating disease progression of Friedreich's ataxia by the International Cooperative Ataxia Rating Scale: analysis of a 603-patient database. Brain 2013;136: 259-268.

40. Tison F, Yekhlef F, Balestre E, et al. Application of the International Cooperative Ataxia Scale rating in multiple system atrophy. Mov Disord 2002;17:1248-1254.

41. Schoch B, Regel JP, Frings M, et al. Reliability and validity of ICARS in focal cerebellar lesions. Mov Disord 2007;22:2162-2169.

42. Salci Y, Fil A, Keklicek H, et al. Validity and reliability of the International Cooperative Ataxia Rating Scale (ICARS) and the Scale for the Assessment and Rating of Ataxia (SARA) in multiple sclerosis patients with ataxia. Mult Scler Relat Disord 2017;18:135-140.

43. D'Abreu A, Franca M Jr, Lopes-Cendes I, Cendes F. The international cooperative ataxia rating scale in Machado-Joseph disease. Comparison with the unified multiple system atrophy rating scale. Mov Disord 2007;22:1976-1979.

44. Burk K, Schulz SR, Schulz JB. Monitoring progression in Friedreich ataxia (FRDA): the use of clinical scales. J Neurochem 2013;126 (suppl 1):118-124.

45. Serrano M, de Diego V, Muchart J, et al. Phosphomannomutase deficiency (PMM2-CDG): ataxia and cerebellar assessment. Orphanet J Rare Dis 2015;10:138.

46. Storey E, Tuck K, Hester R, Hughes A, Churchyard A. Inter-rater reliability of the International Cooperative Ataxia Rating Scale (ICARS). Mov Disord 2004;19:190-192.

47. Itzep D, Martinez-Monseny AF, Bolasell M, et al. Clinical assessment of dysarthria in children with cerebellar syndrome associated with PMM2-CDG. Cerebellum 2018;49:408-413.

48. Loesch DZ, Churchyard A, Brotchie P, Marot M, Tassone F. Evidence for, and a spectrum of, neurological involvement in carriers of the fragile X pre-mutation: FXTAS and beyond. Clin Genet 2005; $67: 412-417$.
49. Kitamura K, Nakayama K, Kosaka S, et al. Diffusion tensor imaging of the cortico-ponto-cerebellar pathway in patients with adult-onset ataxic neurodegenerative disease. Neuroradiology 2008;50:285-292.

50. Richter S, Dimitrova A, Maschke M, et al. Degree of cerebellar ataxia correlates with three-dimensional mri-based cerebellar volume in pure cerebellar degeneration. Eur Neurol 2005;54:23-27.

51. Camargos ST, Marques W Jr, Santos AC. Brain stem and cerebellum volumetric analysis of Machado Joseph disease patients. Arq Neuropsiquiatr 2011;69:292-296.

52. Eichler L, Bellenberg B, Hahn HK, Koster O, Schols L, Lukas C. Quantitative assessment of brain stem and cerebellar atrophy in spinocerebellar ataxia types 3 and 6: impact on clinical status. AJNR Am J Neuroradiol 2011;32:890-897.

53. Kieling C, Rieder CR, Silva AC, et al. A neurological examination score for the assessment of spinocerebellar ataxia 3 (SCA3). Eur J Neurol 2008;15:371-376.

54. Monte TL, Reckziegel ER, Augustin MC, et al. NESSCA validation and responsiveness of several rating scales in Spinocerebellar ataxia type 2. Cerebellum 2017;16:852-858.

55. Azevedo PB, Rocha AG, Keim LMN, et al. Ophthalmological and Neurologic Manifestations in Pre-clinical and Clinical Phases of Spinocerebellar Ataxia Type 7. Cerebellum 2019;18:388-396.

56. Schmitz-Hubsch T, du Montcel ST, Baliko L, et al. Scale for the assessment and rating of ataxia: development of a new clinical scale. Neurology 2006;66:1717-1720.

57. Schmitz-Hubsch T, Fimmers R, Rakowicz M, et al. Responsiveness of different rating instruments in spinocerebellar ataxia patients. Neurology 2010;74:678-684.

58. Weyer A, Abele M, Schmitz-Hubsch T, et al. Reliability and validity of the scale for the assessment and rating of ataxia: a study in 64 ataxia patients. Mov Disord 2007;22:1633-1637.

59. Yabe I, Matsushima M, Soma H, Basri R, Sasaki H. Usefulness of the Scale for Assessment and Rating of Ataxia (SARA). J Neurol Sci 2008;266:164-166.

60. Adanyeguh IM, Perlbarg V, Henry PG, et al. Autosomal dominant cerebellar ataxias: imaging biomarkers with high effect sizes. Neuroimage Clin 2018;19:858-867.

61. Jacobi H, Hauser TK, Giunti P, et al. Spinocerebellar ataxia types 1,2, 3 and 6: the clinical spectrum of ataxia and morphometric brainstem and cerebellar findings. Cerebellum 2012;11:155-166.

62. Matsushima A, Yoshida K, Genno H, et al. Clinical assessment of standing and gait in ataxic patients using a triaxial accelerometer. Cerebellum Ataxias 2015;2:9.

63. Choi SW, Han N. Evaluation of Ataxia in Mild Ischemic Stroke Patients Using the Scale for the Assessment and Rating of Ataxia (SARA). Ann Rehabil Med 2018;42:375-383.

64. Meissner WG, Fernagut PO, Dehay B, et al. Multiple system atrophy: recent developments and future perspectives. Mov Disord 2019;34:1629-1642.

65. Wenning GK, Tison F, Seppi K, et al. Development and validation of the Unified Multiple System Atrophy Rating Scale (UMSARS). Mov Disord 2004;19:1391-1402.

66. Krismer F, Seppi K, Tison F, et al. The Unified Multiple System Atrophy Rating Scale: intrarater reliability. Mov Disord 2012;27: 1683-1685.

67. Meissner WG, Flabeau O, Perez P, et al. Accuracy of portable polygraphy for the diagnosis of sleep apnea in multiple system atrophy. Sleep Med 2014;15:476-479.

68. Shah A, Prasad S, Rastogi B, et al. Altered structural connectivity of the motor subnetwork in multiple system atrophy with cerebellar features. Eur Radiol 2019;29:2783-2791.

69. Lieto M, Roca A, Bruzzese D, et al. Longitudinal study of a cohort of MSA-C patients in South Italy: survival and clinical features. Neurol Sci 2019;40:2105-2109.

70. Assadi M, Leone P, Veloski JJ, Schwartzman RJ, Janson CG, Campellone JV. Validating an Ataxia Functional Composite Scale in spinocerebellar ataxia. J Neurol Sci 2008;268:136-139.

71. Arcuria G, Marcotulli C, Galasso C, Pierelli F, Casali C. 15-White Dots APP-Coo-Test: a reliable touch-screen application for assessing 
upper limb movement impairment in patients with cerebellar ataxias. J Neurol 2019;266:1611-1622.

72. Arcuria G, Marcotulli C, Amuso R, et al. Developing an objective evaluating system to quantify the degree of upper limb movement impairment in patients with severe Friedreich's ataxia. Neurol Sci 2020;41:1577-1587.

73. Tezenas du Montcel S, Charles P, Ribai P, et al. Composite cerebellar functional severity score: validation of a quantitative score of cerebellar impairment. Brain 2008;131:1352-1361.

74. Tanguy Melac A, Mariotti C, Filipovic Pierucci A, et al. Friedreich and dominant ataxias: quantitative differences in cerebellar dysfunction measurements. J Neurol Neurosurg Psychiatry 2018;89: $559-565$.

75. Chan E, Charles P, Ribai P, et al. Quantitative assessment of the evolution of cerebellar signs in spinocerebellar ataxias. Mov Disord 2011;26:534-538.

76. Tezenas du Montcel S, Charles P, Goizet C, et al. Factors influencing disease progression in autosomal dominant cerebellar ataxia and spastic paraplegia. Arch Neurol 2012;69:500-508.

77. Jacobi H, Reetz K, du Montcel ST, et al. Biological and clinical characteristics of individuals at risk for spinocerebellar ataxia types 1,2, 3 , and 6 in the longitudinal RISCA study: analysis of baseline data. Lancet Neurol 2013;12:650-658.

78. Saute JA, Rieder CR, Castilhos RM, et al. Planning future clinical trials in Machado Joseph disease: lessons from a phase 2 trial. J Neurol Sci 2015;358:72-76.

79. Gajos KZ, Reinecke K, Donovan M, et al. Computer mouse use captures ataxia and parkinsonism, enabling accurate measurement and detection. Mov Disord 2020;35:354-358.

80. Schmitz-Hubsch T, Giunti P, Stephenson DA, et al. SCA Functional Index: a useful compound performance measure for spinocerebellar ataxia. Neurology 2008;71:486-492.
81. Burk K, Sival DA. Scales for the clinical evaluation of cerebellar disorders. Handb Clin Neurol 2018;154:329-339.

82. Berry-Kravis E, Lewin F, Wuu J, et al. Tremor and ataxia in fragile X premutation carriers: blinded videotape study. Ann Neurol 2003; 53:616-623.

83. Jacquemont S, Hagerman RJ, Leehey MA, et al. Penetrance of the fragile $\mathrm{X}$-associated tremor/ataxia syndrome in a premutation carrier population. JAMA 2004;291:460-469.

84. Rossi M, Perez-Lloret S, Cerquetti D, Merello M. Movement disorders in autosomal dominant cerebellar ataxias: a systematic review. Mov Disord Clin Pract 2014;1:154-160.

85. Rossi M, Perez-Lloret S, Doldan L, et al. Autosomal dominant cerebellar ataxias: a systematic review of clinical features. Eur J Neurol 2014;21:607-615.

86. Filipovic Pierucci A, Mariotti C, Panzeri M, et al. Quantifiable evaluation of cerebellar signs in children. Neurology 2015;84:12251232 .

87. Jacobi H, Rakowicz M, Rola R, et al. Inventory of Non-Ataxia Signs (INAS): validation of a new clinical assessment instrument. Cerebellum 2013;12:418-428.

88. Hoche F, Guell X, Vangel MG, Sherman JC, Schmahmann JD. The cerebellar cognitive affective/Schmahmann syndrome scale. Brain $2018 ; 141: 248-270$.

\section{Supporting Data}

Additional Supporting Information may be found in the online version of this article at the publisher's web-site. 


\section{SGML and CITI Use Only DO NOT PRINT}

\section{Author Roles}

(1) Research Project: A. Conception, B. Organization, C. Execution; (2) Statistical Analysis: A. Design, B. Execution, C. Review and Critique; (3) Manuscript Preparation: A. Writing of the First Draft, B. Review and Critique.

Santiago Perez Lloret: 1B, 1C, 3A

Bart van de Warrenburg: 1C, 3B

Malco Rossi: 1C, 3B

Carmen Rodríguez-Blázquez: 1C, 3B

Theresa Zesiewicz: 1C, 3B

Jonas A.M. Saute: 1C, 3B

Alexandra Durr: 1C, 3B

Masatoyo Nishizawa: 1C, 3B

Pablo Martinez-Martin: 1A, 1B, 3B

Glenn T. Stebbins: 1A, 1B, 3B

Anette Schrag: 1A, 1B, 3B

Matej Skorvanek: 1A, 1B, 3B

\section{Financial Disclosures}

Santiago Perez Lloret: Stock Ownership in medically related fields: none; Intellectual Property Rights: none; Expert Testimony: none; Advisory Boards/Consultant: Merz Pharmaceuticals; Employment: none; Partnerships: none; Contracts: none; Honoraria: IPMDS; Royalties: none; Grants: FONCyT, CONICET; Other: none.

Bart van de Warrenburg: Stock Ownership in medically related fields, none; Intellectual Property Rights, none; Expert Testimony, none; Advisory Boards/Consultant, none; Employment, none; Partnerships, none; Contracts, none; Honoraria, none; Royalties, none; Grants, Radboud University Medical Centre, Gossweiler Foundation, Hersenstichting, ZonMW, and uniQure; Other, none.

Malco Rossi: Stock Ownership in medically related fields, none; Intellectual Property Rights, none; Expert Testimony, none; Advisory Boards/Consultant, none; Employment, none; Partnerships, none; Contracts, none; Honoraria, none; Royalties, none; Grants, none; Other, none.

Carmen Rodríguez-Blázquez: Stock Ownership in medically related fields, none; Intellectual Property Rights, none; Expert Testimony, none; Advisory Boards/Consultant, none; Employment, Carlos III Institute of Health; Partnerships, none; Contracts, none; Honoraria, none; Royalties, none; Grants, none; Other, none.

Theresa Zesiewicz: Stock Ownership in medically related fields, none; Intellectual Property Rights, patents 9,463,190 and 9,872,404; Expert Testimony, none; Advisory Boards/Consultant, Boston Scientific, Reata Pharm, Steminent Biotherapeutics; Employment, none; Partnerships, none; Contracts, none; Honoraria, Senior Editor Neurodegenerative Disease Management; Royalties, none; Grants, AbbVie, Biogen, Biohaven Pharm, Boston Scientific, Bukwang Pharm, Cala Health, Cavion, FA Research Alliance, Houston Methodist Research Institute, National Institutes of Health, Retrotope, Takeda; Other, none.

Jonas A.M. Saute: Stock Ownership in medically related fields, none; Intellectual Property Rights, none; Expert Testimony, none; Advisory Boards/Consultant, Sarepta - limb-girdle muscular dystrophy; Employment, none; Partnerships, none; Contracts, none; Honoraria, none; Royalties, none; Grants, Conselho Nacional de Desenvolvimento Científico e Tecnológico (CNPq), Brazil - hereditary spastic paraplegias; Other, none.

Alexandra Durr: Stock Ownership in medically related fields, none; Intellectual Property Rights, none; Expert Testimony, none; Advisory Boards/Consultant, none; Employment, none; Partnerships, none; Contracts, none; Honoraria, none; Royalties, none; Grants, none; Other, none.

Masatoyo Nishizawa: Stock Ownership in medically related fields, none; Intellectual Property Rights, none; Expert Testimony, none; Advisory Boards/Consultant, Kissei Pharmaceuticals; Employment, Niigata University of Health and Welfare; Partnerships, none; Contracts, none; Honoraria, none; Royalties, none; Grants, none; Other, none. 
Pablo Martinez-Martin: Stock Ownership in medically related fields, none; Intellectual Property Rights, none; Expert Testimony, none; Advisory Boards/Consultant, Bial, for advice in clinical-epidemiological study; Employment, retired; Partnerships, none; Contracts, none; Honoraria, National School of Public Health (ISCIII), Britannia, and Editorial Viguera for lecturing in courses or publications, from International Parkinson and Movement Disorder Society (IPMDS) for management of the Program on Rating Scales; Royalties, none; Grants, IPMDS for development and validation of the MDS-NMS; Other, IPMDS financial support for attending the IPMDS International Congress 2019.

Glenn T. Stebbins: Consulting and Advisory Board Membership with honoraria, Acadia, Pharmaceuticals, Adamas Pharmaceuticals, Inc., Biogen, Inc., Ceregene, Inc., CHDI Management, Inc., Cleveland Clinic Foundation, Ingenix Pharmaceutical Services (i3 Research), MedGenesis Therapeutix, Inc., Neurocrine Biosciences, Inc., Pfizer, Inc., Tools-4-Patients, Ultragenyx, Inc., Sunshine Care Foundation; Grants and Research, National Institutes of Health, Department of Defense, Michael J. Fox Foundation for Parkinson's Research, Dystonia Coalition, CHDI, Cleveland Clinic Foundation, International Parkinson and Movement Disorder Society, CBD Solutions; Honoraria, International Parkinson and Movement Disorder Society, American Academy of Neurology, Michael J. Fox Foundation for Parkinson's Research, US Food and Drug Administration, National Institutes of Health, Alzheimer's Association; Intellectual Property Rights: none; Ownership interests: none; Royalties: none; Expert Testimony: none; Salary: Rush University Medical Center.

Anette Schrag: Stock Ownership in medically related fields, none; Consultancies, Biogen, AbbVie, PD Neurotechnology 2020; Advisory Boards, Biogen, Bial; Partnerships, none; Honoraria, Biogen, AbbVie; Grants, European Commission, Parkinson's UK, GE Healthcare, Economic and Social Research Council (ESRC), International Parkinson and Movement Disorders Society, University College London, National Institutes of Health, National Institute for Health Research (NIHR) ULCH Biomedical Research Centre; Intellectual Property Rights, none; Royalties, Oxford University Press; Expert Testimony, none; Employment, University College London NHS, National Institute for Health Research UCL Biomedical Research Centre; Contracts, none; Conference attendance support, none; Royalties, Oxford University Press for Rating Scales in PD, University College London Business.

Matej Skorvanek: Stock Ownership in medically related fields, none; Intellectual Property Rights, none; Expert Testimony, none; Advisory Boards/Consultant, Biogen, AbbVie; Employment, PJ Safarik University, University Hospital L. Pasteur; Partnerships, none; Contracts, none; Honoraria, AbbVie, Biogen, Medtronic, Boston Scientific, Krka, TEVA, Desitin, Sandoz, IPMDS; Royalties, none; Grants, Slovak Research and Development Agency, Slovak Grant Agency, IBM. Other, none. 